\title{
Attention allocation to ambiguous health/somatic threat cues
}

Citation for published version (APA):

Schrooten, M., Vancleef, L., \& Vlaeyen, J. W. S. (2015). Attention allocation to ambiguous health/somatic threat cues. European Journal of Pain, 19(7), 1002-1011. https://doi.org/10.1002/ejp.628

Document status and date:

Published: 01/08/2015

DOI:

10.1002/ejp.628

Document Version:

Publisher's PDF, also known as Version of record

Document license:

Taverne

Please check the document version of this publication:

- A submitted manuscript is the version of the article upon submission and before peer-review. There can be important differences between the submitted version and the official published version of record.

People interested in the research are advised to contact the author for the final version of the publication, or visit the DOI to the publisher's website.

- The final author version and the galley proof are versions of the publication after peer review.

- The final published version features the final layout of the paper including the volume, issue and page numbers.

Link to publication

\footnotetext{
General rights rights.

- You may freely distribute the URL identifying the publication in the public portal. please follow below link for the End User Agreement:

www.umlib.nl/taverne-license

Take down policy

If you believe that this document breaches copyright please contact us at:

repository@maastrichtuniversity.nl

providing details and we will investigate your claim.
}

Copyright and moral rights for the publications made accessible in the public portal are retained by the authors and/or other copyright owners and it is a condition of accessing publications that users recognise and abide by the legal requirements associated with these

- Users may download and print one copy of any publication from the public portal for the purpose of private study or research.

- You may not further distribute the material or use it for any profit-making activity or commercial gain

If the publication is distributed under the terms of Article $25 \mathrm{fa}$ of the Dutch Copyright Act, indicated by the "Taverne" license above, 


\title{
Attention allocation to ambiguous health/somatic threat cues
}

\author{
M.G.S. Schrooten ${ }^{1,2}$, L. Vancleef ${ }^{3}$, J.W.S. Vlaeyen ${ }^{2,3}$ \\ 1 Center for Health and Medical Psychology (CHAMP), Örebro University, Sweden \\ 2 Research Group Health Psychology, University of Leuven, Belgium \\ 3 Department of Clinical Psychological Science, Maastricht University, The Netherlands
}

\begin{abstract}
Correspondence
Martien G.S. Schrooten

E-mail: martien.schrooten@oru.se

Funding sources

The contribution of MGSS and JWSV was supported by the Odysseus Grant 'The Psychology of Pain and Disability Research Program' funded by the Research Foundation - Flanders (FWO Vlaanderen, Belgium) and by the NWO Social Sciences Research Council of the Netherlands, grant no. 453-04-003. MGSS was also supported by a research fellowship from Örebro University, Sweden. LV was sponsored by NWO Social Sciences Research Council of the Netherlands, VENI grant no. 451-09-026.
\end{abstract}

\section{Conflict of interest}

The authors have no conflicts of interest to declare.

\section{Accepted for publication}

18 October 2014

Submitted as original article. The reported research was conducted at the Department of Clinical Psychological Science, Maastricht University.

doi:10.1002/ejp.628

\begin{abstract}
Background: An influential idea is that attentional bias to information related to pain or pain-related negative affect underlies persistent pain problems. Such information is however often ambiguous. If ambiguous input is perceived as pain or threat related, attention to this stimulus would be enhanced compared with stimuli with no (dominant) pain-/threat-related meaning. Attentional bias to ambiguous stimuli related to somatic/health threat was expected to be more pronounced with higher levels of pain catastrophizing.

Methods: University students performed a spatial cueing task including four types of word cues that were combinations of word content (somatic/health threat vs. non-threat), and word ambiguity (unambiguous vs. ambiguous), each presented for 500 or $750 \mathrm{~ms}$. Attentional bias to somatic/health threat is reflected in larger cue validity effects for somatic/heath threat words than for non-threat words.

Results: In the 500-ms condition, cue validity effects were larger for threat than for non-threat words in participants reporting low catastrophizing, but did not depend on word content in participants reporting higher catastrophizing. In the 750 -ms condition, cue validity effects did not depend on pain catastrophizing or word content. Cue validity effects did not significantly differ between unambiguous words and ambiguous homographs.

Conclusions: Low catastrophizers demonstrated attentional bias to threat content. Participants reporting higher catastrophizing showed overall enhanced attentional orienting. There was no evidence for differences in (biased) attention to unambiguous and ambiguous words. Further research is needed to determine attentional bias for ambiguous pain-/threat-related stimuli in the context of consistent attentional bias for unambiguous pain-/threat-related stimuli.
\end{abstract}

\section{Introduction}

Understanding selective information processing in different pain conditions is pivotal to a better understanding of (chronic) pain and pain-related distress. This central notion (Eccleston and Crombez, 1999; Van Damme et al., 2010; Vlaeyen and Linton, 2012) has prompted systematic experimental research on biased attention to information that refers to pain or pain-related negative affect (Schoth et al., 2012;
Crombez et al., 2013). These studies have been largely motivated by two considerations. First, from an evolutionary perspective, preferential processing of pain signals assists rapid adaptive responding to expected pain and harm (Van Damme et al., 2004). By orienting attention to environmental signals and other cues that inform about pain outcomes, pain can be anticipated and avoided. Second, behavioural and emotional pain responses are proposed to be influenced by cognitive appraisals and expectations about pain (Pincus and 


\section{What's already known about this topic?}

- While findings for pain-related attentional bias are mixed, they tend to suggest that the size and nature of such bias critically depend on the interaction of different factors, including stimulus characteristics, study population, current pain context and affective-motivational states.

- Notwithstanding considerable progress in understanding pain-related attentional bias, attentional processing of stimuli with an ambiguous relation to pain or somatic (health) threat remains largely unexplored.

\section{What does this study add?}

- This study is the first specifically designed to evaluate attentional bias to ambiguous pain/ threat-related information.

- This study extends previous work by examining attention to somatic/health threat words with a spatial cueing task, taking into account stimulus ambiguity, processing time and pain catastrophizing.

Morley, 2001; Vlaeyen and Linton, 2012). Concerns and negative expectations about pain (control) are thought to be associated with enhanced, prioritized attention to information that matches the content of pain-related concerns, memories and/or schemata.

However, signals are not always clear in their predictions regarding pain outcomes and information is often ambiguous. Although such uncertainty and ambiguity can pose substantial problems for selection of meaning and action, biased attention to stimuli with an uncertain or ambiguous relation to pain or physical (health) threat remains largely unexplored.

Individuals with pain-related concerns, such as those who are high on pain catastrophizing or painrelated anxiety, are likely to evaluate ambiguous information negatively, as suggested by empirical evidence on negative interpretation bias (Keogh and Cochrane, 2002; Keogh et al., 2004; Vancleef et al., 2009). Interpretation bias refers here to the tendency to have selective access to the pain-related or physical threat meaning of ambiguous stimuli, and could be explained by attentional priority given to the pain or threat meaning rather than to other meanings of the stimulus (cf. Mathews and Mackintosh, 1998). Similarly, one might expect that if ambiguous input is negatively evaluated and perceived as related to pain or threat, attention to this stimulus is enhanced as compared with stimuli that have no (dominant) pain- or threatrelated meaning.
The present experiment is a first step in examining attentional bias for both unambiguous and ambiguous stimuli related to somatic/health threat. Corroborating and extending earlier research (Schoth et al., 2012; Crombez et al., 2013), we expected an attentional bias to unambiguous somatic/health threat words, especially in those scoring high on pain catastrophizing. Also, we hypothesized that there would be an attentional bias to ambiguous somatic/health threat words, which would be greater in those who score high, compared with low, in catastrophizing. Furthermore, taking into account processing time of ambiguous meaning, we expected bias for ambiguous words to become apparent only with longer word presentation durations than bias for unambiguous threat materials (cf. Richards, 2004; Richards and French, 1992).

\section{Methods}

\subsection{Participants}

We selected students with either low or higher scores on the Pain Catastrophizing Scale (PCS; see below), the most commonly used questionnaire measure of pain catastrophizing (Walton et al., 2013). Selection was based on the student's aggregate PCS score (across all 13 items) collected during larger scale screening sessions among first-year students at Maastricht University (Faculty of Psychology and Neuroscience and Faculty of Health, Medicine and Life Sciences). Those scoring at or below the 35 th percentile (score 10) or at or above the 65 th percentile (score 15) of the initial screening distribution were invited to participate in two testing sessions (see Procedure) in exchange for one $€ 10$ voucher or two research course credits. Altogether, 35 volunteers with low scores and 30 with relatively high scores were tested. However, 14 participants were excluded from data analyses because they scored low on PCS during screening but at or above the median PCS score at test (score 12; see below), or scored relatively high during screening but at or below the median PCS score at test.

The final sample consisted of 27 participants reporting low levels of pain catastrophizing (LPC) and 24 reporting higher levels of pain catastrophizing (HPC). All participants had excellent Dutch language skills and (corrected to) normal vision, and did not have dyslexia. All gave informed consent. The Ethics Committee of the Faculty of Psychology and Neuroscience (Maastricht University) approved the study.

\subsection{PCS}

The PCS consists of 13 items describing thoughts and feelings when suffering from pain (Sullivan et al., 1995). Participants indicate the degree to which they experience each of those thoughts or feelings when experiencing pain on a 5-point Likert scale, ranging from 0 (not at all) to 4 (all the time). 
PCS has demonstrated sound psychometric properties, also in student samples (Sullivan et al., 1995; Osman et al., 1997; Van Damme et al., 2000, 2002).

\subsection{Single-cue modified spatial cueing task}

\subsubsection{Word stimuli}

Critical stimuli were 64 Dutch words of four types, based on whether or not they were related to health threat or somatic threat and on whether or not they were ambiguous in the sense of having multiple meanings. There were 16 unambiguous words only related to health threat or somatic threat (THR; e.g. tumor meaning tumour; onwel meaning unwell/ill/ indisposed); 16 ambiguous homographs having meanings related to health threat or somatic threat as well as meanings not related to health threat or somatic threat [AMB-THR; e.g. uitslag meaning either rash (skin) or result/outcome (e.g. in elections); lam meaning either paralysed or lamb]; 16 unambiguous words not related to threat (NOTHR; e.g. trompet meaning trumpet; ovaal meaning oval); 16 ambiguous homographs having only non-threat meanings [AMB-NOTHR; e.g. meer meaning either (water) lake or more (often)/further; bank meaning either bench/couch/sofa or bank (monetary)]. AMB-NOTHR words were included to control for the effect of lexical ambiguity per se. Unambiguous words were taken from previous pain research (e.g. Hermans and De Houwer, 1994; Roelofs et al., 2005; Vancleef et al., 2007). Ambiguous words were selected from an initial pool of 85 Dutch homographs on the basis of ratings of whether the different homograph meanings are related to physical pain, illness, physical invalidity or neither. These ratings were collected from undergraduates in an independent pilot study at Maastricht University. It should be noted that word categories differed in terms of word length (in letters), $F(3,60)=6.3, p=0.001$, with AMB-NOTHR words (i.e. the additional control words) being on average shorter [mean $=4.4$; standard deviation $(\mathrm{SD})=1.09$; range 3-6] than NOTHR words (mean $=7.1$; $\mathrm{SD}=1.93$; range 4-11; Bonferroni-corrected $p=0.001$ ), AMB-THR words $($ mean $=6.6 ; \quad \mathrm{SD}=2.19$; range $3-11$; Bonferroni-corrected $p=0.01$ ) and, although nonsignificantly so, THR words (mean $=6.0 ; \mathrm{SD}=1.97$; range 4-10; Bonferroni-corrected $p=0.12$ ). There were no differences in terms of word length between the most relevant word categories THR, AMB-THR and NOTHR words (Bonferroni-corrected $p s>0.5$ ). During practice trials, 32 additional emotionally neutral unambiguous words (mean word length $=5.3 ; \mathrm{SD}=1.21$; range 3-7 letters) were presented, taken from previous anxiety research (e.g. Schrooten and Smulders, 2009, 2010).

\subsubsection{Cueing task}

A single-cue modified spatial cueing task was used to investigate biased attentional orienting for threat cues (cf. Fox et al., 2001; adapted from Posner et al., 1987). This wellestablished paradigm has been widely applied to examine attentional bias to a variety of visual threat-related stimuli (e.g. Amir et al., 2003; Broomfield and Turpin, 2005; Fox et al., 2001; Koster et al., 2006; Ellenbogen and Schwartzman, 2009; Waters et al., 2007; Yiend and Mathews, 2001) and has also been successfully applied in pain research to study attentional bias for conditioned pain signals in otherwise pain-free undergraduates (e.g. Schrooten et al., 2012b; Van Damme et al., 2004; Van Ryckeghem et al., 2012) and for pain/threat words in patients with abdominal pain and their healthy controls (e.g. Martin and Chapman, 2010).

Throughout the task, a black central fixation cross (+) was presented on a light grey background at the centre of the computer screen. Five-hundred milliseconds after the onset of each trial one word (the cue) appeared in black uppercase letters (non-proportional font, $0.5 \mathrm{~cm}$ high) at the left or right of fixation with the inner edge of the word at approximately $3 \mathrm{~cm}$ from screen centre. Two versions of the task were created that were identical except for word presentation duration. In one version all words were displayed for $500 \mathrm{~ms}$; in the other version for $750 \mathrm{~ms}$. The choice of these specific time frames was motivated by the following considerations. In research on pain-related or anxiety-related attentional bias to unambiguous (word) stimuli, it is common to present stimuli for $500 \mathrm{~ms}$ (e.g. Asmundson et al., 2005; Boston and Sharpe, 2005; Burns et al., 2010; Keogh et al., 2001b; Lees et al., 2005). In addition, evidence has been reported that although both threat and non-threat meanings of ambiguous words are initially activated, it takes about $750 \mathrm{~ms}$ for one meaning to become dominant and enter awareness in high-anxious individuals (Richards and French, 1992; Richards, 2004). Immediately following the display of the word (i.e. at word offset), a small target (' $/$ ' or ' ; $4 \mathrm{~mm}$ ) appeared at the same side of fixation as the foregoing word (validly cued trials) or at the opposite side (invalidly cued trials). Participants' task was to classify probe identity (' $/$ ' or ' $\mid$ '?) on each trial by pressing as quickly and as accurately as possible the top key on a response box with the right index finger to ' $T$ ' and the bottom key with the left index finger to ' $\%$ '. Targets were displayed until a response was made or for max. $2000 \mathrm{~ms}$. Inter-trial interval was $750 \mathrm{~ms}$. Incorrect and premature responses to targets were indicated by a short beep along with the display of an error message at screen centre for $500 \mathrm{~ms}$ (+1000 ms pause). Missed responses to these targets were also followed by a visual message lasting $500 \mathrm{~ms}$ (+1000 ms pause).

Attention to peripheral word cues is reflected in faster responses to targets on validly cued trials than on invalidly cued trials (i.e. cue validity effect; Posner et al., 1980; Yantis, 1996). Note that longer time intervals (>300 ms) between the onset of the cue and the onset of the target, like in the present task, might actually result in the opposite effect: slower responses on validly cued trials than on invalidly cued trials (Klein, 2000; Fox et al., 2002). This so-called inhibition of return effect is, however, eliminated if the proportion of valid trials is higher than $50 \%$ and with target classification tasks (Klein and Taylor, 1994). Therefore, with the present 
task parameters, we expected a standard cue validity effect, with faster responses on validly cued trials than on invalidly cued trials. Biased attention to threat words is reflected in larger cue validity effects for threat words than for nonthreat words (Fox et al., 2001). The size of attentional bias effects as measured with the spatial cueing task is in the order of milliseconds. The impact of ambiguity on (biased) attention orienting is reflected in differential cue validity effects for ambiguous and unambiguous (threat and/or nonthreat) words.

The modified spatial cueing task consisted of 32 practice trials, followed by 256 experimental trials, organized into four test blocks of 64 trials. During each test block, all 64 critical words were presented once. For each combination of word type, word position and target type, there were an equal number of trials three-fourths of which were validly cued and one-fourth invalidly cued. During self-paced breaks after every 32nd trial (i.e. in the middle of each test block and in between test blocks) performance feedback was presented at the screen [mean reaction time (RT); number of incorrect responses] in order to maintain participants' motivation throughout the RT task. Experimental trials were presented in a different random order for each participant. Participants were informed that on most trials the target would occur at the same side of the cross as the preceding word, but they were instructed to fixate the cross at all times. No further instruction was given to process the words in any particular way. All task instructions appeared on the computer screen.

\subsection{Apparatus}

Cueing task presentation and response registration were controlled by a Dell Optiplex 755 computer, running Presentation software (Neurobehavioral Systems, Albany, CA, USA) and connected to a response box, QWERTY keyboard, computer mouse and two 19-in. Samsung Syncmaster 931 BF LCD monitors $(1920 \times 1080$ resolution; one for the participant and one for the experimenter).

\subsection{Procedure}

Participants were invited to two testing sessions, with 4-7 days between sessions. During both sessions, participants were individually tested in a dimly lit testing room. Upon arrival at the testing room, participants were comfortably seated at a viewing distance of $\sim 60 \mathrm{~cm}$ from the computer screen. They could communicate with the experimenter through an intercom. They were informed that the study investigated cognitive functioning. The true purpose was explained after all participants had been tested. At the start of the first session, written informed consent was obtained based on general information describing tasks and sessions. During one session participants performed the modified spatial cueing task with 500-ms word presentation duration; during the other session they performed the same task but with 750-ms word presentation duration. ${ }^{1}$ The order of the 500-ms session and the 750-ms session was counterbalanced across participants. At the end of the second session, all participants completed a battery of questionnaires via a secure online system. This battery included a Dutch version of the PCS. ${ }^{2}$ Upon questionnaire completion participants received their compensation (two research course credits or one $€ 10$ voucher) for participating.

\subsection{Design}

A mixed analysis of variance (ANOVA) factorial design with cue validity (2: valid vs. invalid), word content (threat vs. non-threat) and word ambiguity (unambiguous vs. ambiguous) as within-subject factors and pain catastrophizing (2: LPC vs. HPC) as between-subject factor was used to evaluate catastrophizing-related attentional bias effects for each modified spatial cueing task separately. The prediction is that cue validity effects (i.e. faster RTs on valid than on invalid trials) should be larger for threat word cues than for non-threat word cues. This pattern is expected to be particularly pronounced in HPC as compared with LPC. Taken together, we predicted a significant three-way interaction between cue validity, word content and pain catastrophizing. Importantly, we expected similar cue validity $\times$ word content $\times$ pain catastrophizing interactions for ambiguous threat words as for unambiguous threat words. However, a differential time course of attentional bias for ambiguous and unambiguous threat words - with bias for unambiguous threat words being particularly strong at 500-ms word presentation duration and bias for ambiguous threat words becoming apparent only at 750-ms word presentation duration - would be reflected in significant four-way interactions between cue validity, word content, word ambiguity and pain catastrophizing for both word presentation durations.

\section{Results}

\subsection{Group characteristics}

Within the final sample, the HPC group had a higher PCS score at test $($ mean $=21.3 ; \mathrm{SD}=7.1)$ than the LPC group $($ mean $=8.3 ; \mathrm{SD}=3.1), t(30.6)=8.3, p<0.001$ (equality of variances not assumed). The mean PCS score of the HPC group was in the seventh decile of norm scores for undergraduates; the mean PCS score of the LPC group was in the first decile (Van Damme et al., 2000). The groups differed neither in age,

${ }^{1}$ In each session, the cueing task was followed by an incidental learning task, the results of which will be reported separately. ${ }^{2}$ This battery also included the Fear of Pain QuestionnaireShort Form (Asmundson et al., 2008), Anxiety Sensitivity Index (Peterson and Reiss, 1992) and Injury/Illness Sensitivity Index (Carleton et al., 2005), but these were used for other purposes than the present experiment. 
Table 1 Mean RTs (in ms; 95\% confidence intervals in parentheses) on cueing task trials as a function of word presentation duration, group, word type and cue validity.

\begin{tabular}{|c|c|c|c|c|c|c|}
\hline Word duration & Group & Word type & Valid & Invalid & Cue validity effect & $t(d f)^{a}$ \\
\hline \multirow[t]{8}{*}{$500 \mathrm{~ms}$} & \multirow[t]{4}{*}{$\mathrm{HPC}(n=22)$} & THR & $456.1(428.4-483.7)$ & $500.8(466.5-535.1)$ & $44.8(27.8-61.7)$ & $t(21)=5.2^{\star * *}$ \\
\hline & & AMB-THR & $460.4(433.9-487.0)$ & $494.4(463.1-525.8)$ & $34.0(18.4-49.6)$ & $t(21)=3.5^{\star \star}$ \\
\hline & & NOTHR & $455.2(427.0-483.4)$ & $507.6(475.4-539.8)$ & $52.4(35.5-69.3)$ & $t(21)=5.1 * * *$ \\
\hline & & AMB-NOTHR & $457.9(429.4-486.4)$ & $499.8(466.9-532.7)$ & $41.9(25.5-58.3)$ & $t(21)=4.8^{\star * *}$ \\
\hline & \multirow[t]{4}{*}{ LPC $(n=24)$} & THR & $439.7(413.2-466.2)$ & $475.6(442.8-508.5)$ & $35.9(19.7-52.1)$ & $t(23)=4.4^{\star * \star}$ \\
\hline & & AMB-THR & $442.6(417.1-468.0)$ & $477.8(447.8-507.9)$ & $35.3(20.3-50.2)$ & $t(23)=6.7^{* \star *}$ \\
\hline & & NOTHR & $443.8(416.8-470.8)$ & $462.6(431.8-493.4)$ & $18.7(2.6-34.9)$ & $t(23)=3.1 * \star$ \\
\hline & & AMB-NOTHR & $440.7(413.4-468.0)$ & $465.8(434.3-497.3)$ & $25.1(9.4-40.7)$ & $t(23)=3.5^{\star *}$ \\
\hline \multirow[t]{8}{*}{$750 \mathrm{~ms}$} & \multirow[t]{4}{*}{$\mathrm{HPC}(n=23)$} & THR & $443.5(419.8-467.2)$ & $481.0(454.7-507.3)$ & $37.5(22.1-53.0)$ & $t(22)=4.5^{\star * \star}$ \\
\hline & & AMB-THR & $447.3(423.3-471.4)$ & $479.0(448.5-509.4)$ & $31.6(13.6-49.7)$ & $t(22)=3.3^{\star *}$ \\
\hline & & NOTHR & $445.6(420.7-470.5)$ & $475.5(448.4-502.6)$ & $29.9(12.7-47.1)$ & $t(22)=3.0^{\star *}$ \\
\hline & & AMB-NOTHR & $445.8(421.9-469.7)$ & $486.9(459.8-514.0)$ & $41.1(26.4-55.7)$ & $t(22)=5.2^{\star * *}$ \\
\hline & \multirow[t]{4}{*}{$\operatorname{LPC}(n=26)$} & THR & $441.4(419.1-463.7)$ & $468.7(444.0-493.4)$ & $27.3(12.7-41.8)$ & $t(25)=4.1^{\star \star *}$ \\
\hline & & AMB-THR & $442.6(420.0-465.2)$ & $472.9(444.3-501.5)$ & $30.3(13.3-47.2)$ & $t(25)=3.8^{* \star *}$ \\
\hline & & NOTHR & $445.1(421.7-468.5)$ & $470.7(445.2-496.2)$ & $25.6(9.4-41.8)$ & $t(25)=3.8^{* * *}$ \\
\hline & & AMB-NOTHR & $442.1(419.7-464.6)$ & $468.6(443.1-494.1)$ & $26.5(12.7-40.2)$ & $t(25)=4.2^{\star * \star}$ \\
\hline
\end{tabular}

Reported significance levels are two tailed. AMB-THR, ambiguous threat word; AMB-NOTHR, ambiguous non-threat word; RT, reaction time (after error and RT outlier exclusion); cue validity effect = (mean RT invalid cue - mean RT valid cue); HPC, participants reporting higher levels of pain catastrophizing; LPC, participants reporting low levels of pain catastrophizing; NOTHR, unambiguous non-threat word; THR, unambiguous threat word.

$\star \star p \leq 0.01$.

$* * \star p \leq 0.001$.

${ }^{a}$ One-sample $t$-test contrasting cue validity effect against 0 (no effect).

$t(49)=0.29, p=0.8$ (LPC: mean 20.2 years; $\mathrm{SD}=2.50$; HPC: mean $=20.0$ years; $S D=3.06)$ nor in gender ratio, $\chi^{2}(51)=2.3, p=0.13$ (M:F; LPC: 11:16; HPC: $5: 19)$.

\subsection{Modified spatial cueing task}

\subsubsection{Data preparation}

From the final sample, two LPC participants took part in only one testing session; all other participants in both sessions. In addition, two LPC participants and three HPC participants were mistakenly presented with the same tasks during both sessions (see below); their second session data were discarded. This means that 24 LPC participants and 22 HPC participants completed the task with 500-ms word presentation duration; 26 LPC participants and 23 HPC participants completed the task with 750-ms word presentation duration; 23 LPC participants and 21 HPC participants completed both tasks. Because not all participants performed both tasks, separate analyses were conducted for performance on the task with 500-ms word presentation duration and for performance on the task with 750-ms word presentation duration (see also below, Footnote 3).

Per task, mean percentage incorrect responses on test trials was $4.4 \% \quad(S D=3.0$, range $=0.4-15.2 \%)$ and mean percentage of outlier responses (>final sample mean $+2.5 \mathrm{SD}$ ) on correct test trials was $2.5 \%$ $(\mathrm{SD}=0.8$, range $=0.4-5.3 \%)$. Incorrect responses and correct outlier responses were eliminated from the data. In the final sample, on average $93.2 \%(\mathrm{SD}=3.0$, range $=82.0-98.1 \%$ ) of the data per task remained for analyses.

The results section focuses on RT analyses, for there was not enough variability in the error rates to allow for parametric analyses. The reported analyses were performed on mean RTs. Essentially, the same pattern was obtained with median RTs (with or without outlier exclusion). Because test block did not interact with any of the critical factors (or interactions), the data were collapsed across test blocks. Table 1 presents mean RTs and cue validity effects for each experimental condition (across test blocks). Magnitude of cue validity effects was calculated by subtracting mean RTs on valid trials from mean RTs on invalid trials.

\subsubsection{Analyses of variance}

Per word presentation duration ${ }^{3}$, mean RTs were submitted to an ANOVA with cue validity (two: valid vs.

${ }^{3}$ An ANOVA on mean RT with word presentation duration (2: 500 vs. $750 \mathrm{~ms}$ ), cue validity, word content and word ambiguity as within-subject factors and pain catastrophizing (2) as between-subject factor revealed a trend-level signifi- 


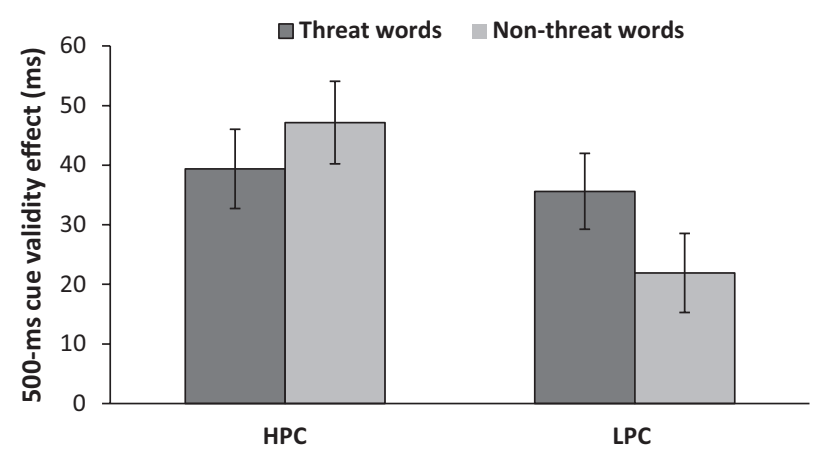

Figure 1 Mean cue validity effects of participants reporting low levels of pain catastrophizing (LPC; $n=24$ ) and participants reporting higher levels of pain catastrophizing (HPC; $n=22$ ) for threat words and non-threat words (pooled over ambiguous and unambiguous ones) with 500-ms word presentation duration. Magnitude of cue validity effects was calculated by subtracting mean reaction times (RTs) on valid trials from mean RTs on invalid trials. Error bars indicate the standard error of the group average of cue validity effects in each condition.

invalid), word content (threat vs. non-threat), word ambiguity (unambiguous vs. ambiguous) and pain catastrophizing (LPC vs. HPC) as factors. With 500-ms word presentation duration, responses were faster on validly cued trials than on invalidly cued trials, $F(1$, $44)=74.6, p<0.001, \eta_{\mathrm{p}}{ }^{2}=0.63$. The magnitude of this cue validity effect depended on word content as well as on pain catastrophizing (cue validity $\times$ word content $\times$ pain catastrophizing: $F(1,44)=6.1, \quad p<$ $\left.0.05, \eta_{\mathrm{p}}^{2}=0.12\right)$, suggesting catastrophizing-related differences in cue validity effects depending on whether or not the word cues were related to health/ somatic threat (see Fig. 1). There were no other significant results from this ANOVA [cue validity $\times$ pain catastrophizing: $\quad F(1,44)=3.0, \quad 0.05<p<0.1$, $\eta_{\mathrm{p}}{ }^{2}=0.06$; word content $\times$ pain catastrophizing, $F(1$, $44)=3.8, \quad 0.05<p<0.1, \quad \eta_{\mathrm{p}}^{2}=0.08 ; \quad$ other effects: $\left.F_{\mathrm{s}}<2.2, p \mathrm{~s}>0.14, \eta_{\mathrm{p}}{ }^{2} \mathrm{~s}<0.05\right]$. These results suggest

cant interaction between word presentation duration, cue validity, word content and pain catastrophizing, $F(1$, $42)=3.0,0.05<p<0.1, \eta_{\mathrm{p}}{ }^{2}=0.07$. This four-way interaction superseded a significant cue validity effect, $F(1$, $42)=64.9, \quad p<0.001, \quad \eta_{\mathrm{p}}{ }^{2}=0.61 ; \quad$ a significant word content $\times$ pain catastrophizing interaction, $F(1,42)=4.1$, $p<0.05, \eta_{\mathrm{p}}{ }^{2}=0.09$, and a significant word content $\times$ cue validity $\times$ pain catastrophizing interaction, $F(1,42)=5.4$, $p<0.05, \eta_{\mathrm{p}}{ }^{2}=0.12$. There were no other (trend-level) significant effects from this ANOVA, $F \mathrm{~s}<1.9, p \mathrm{~s}>0.17$, $\eta_{\mathrm{p}}{ }^{2} \mathrm{~s} \leq 0.04$. The four-way interaction could be taken to allow separate analyses per word presentation duration. Note that this analysis only included participants who completed both task versions (23 LPC participants; 21 HPC participants). that catastrophizing-related cue validity effects did not differ according to word ambiguity. With 750-ms word presentation duration, responses were faster on validly cued trials than on invalidly cued trials, $F(1$, $47)=43.1, p<0.001, \eta_{\mathrm{p}}{ }^{2}=0.48$. There were no other significant results from this ANOVA, $F \mathrm{~s}<2.5$, $p s>0.12, \eta_{\mathrm{p}}^{2} \mathrm{~s}<0.05$.

To break down the three-way interaction for 500-ms word presentation duration, a series of $2 \times 2$ ANOVAs were carried out. First, for each catastrophizing group separately, mean RTs were submitted to an ANOVA with cue validity (2) and word content (2) as factors. For the HPC group, the cue validity effect did not significantly depend on word content [cue validity $\times$ word content: $F(1,21)=1.2, p=0.29, \eta_{\mathrm{p}}{ }^{2}=0.05$; cue validity: $F(1,21)=43.2, p<0.001, \eta_{\mathrm{p}}{ }^{2}=0.67$; word content: $F<1.0]$. However, for the LPC group, the cue validity effect was significantly larger for threat words than for non-threat words [cue validity $\times$ word content: $F(1,23)=7.4, p<0.05, \eta_{\mathrm{p}}{ }^{2}=.24$; cue validity: $F(1,23)=30.2, \quad p<0.001, \quad \eta_{\mathrm{p}}{ }^{2}=0.57$; word content: $\left.F(1,23)=7.1, p<0.05, \eta_{\mathrm{p}}{ }^{2}=0.24\right]$ with a mean difference in cue validity effect of $13.7 \mathrm{~ms}$ [95\% confidence interval (CI): 3.3-24.2]. Second, for each type of word content separately, mean RTs were submitted to an ANOVA with cue validity (2) and pain catastrophizing (2) as factors. For threat words (pooled over ambiguous and unambiguous ones), there was no significant group difference [cue validity $\times$ pain catastrophizing: $F<1.0$; cue validity: $F(1,44)=66.3$, $p<0.001, \eta_{\mathrm{p}}^{2}=0.60$; pain catastrophizing: $\left.F<1.0\right]$. However, for non-threat words (pooled over ambiguous and unambiguous ones), the HPC group showed a significantly larger cue validity effect than the LPC group [cue validity $\times$ pain catastrophizing: $F(1,44)=6.9, \quad p<0.05, \quad \eta_{\mathrm{p}}{ }^{2}=0.14 ; \quad$ cue validity: $F(1,44)=51.8, p<0.001, \eta_{\mathrm{p}}{ }^{2}=0.54$; pain catastrophizing: $\left.F(1,44)=1.8, p=0.18, \eta_{\mathrm{p}}{ }^{2}=0.04\right]$ with a mean difference in cue validity effect of $25.2 \mathrm{~ms}$ (95\% CI: 5.9-44.6).

To summarize, with 500-ms word presentation duration, the LPC group showed a larger cue validity effect for threat words than for non-threat words. The HPC group showed a similar cue validity effect for threat words and non-threat words with this effect being larger than the cue validity effect shown by the LPC group for non-threat words. Essentially, the same conclusions were reached when these analyses were restricted to unambiguous and ambiguous threat words, and unambiguous non-threat words (see Supplementary Appendix, online), not taking into account the relatively short ambiguous non-threat words (see Methods). 


\section{Discussion}

We aimed to test the hypothesis of an attentional bias, not only for unambiguous, but also for ambiguous health/somatic threat words, especially pronounced in high pain catastrophizing individuals. Attentional bias for threat-related information is reflected in larger cue validity effects for threat words than for non-threat words. The impact of word processing time was taken into account by presenting words for 500 and $750 \mathrm{~ms}$.

The results partially support our predictions. Analyses revealed that cue validity effects with 500-ms (but not 750-ms) word presentation depended on threat word content and catastrophizing. However, the precise pattern of results was not exactly as predicted: low catastrophizers showed a larger cue validity effect to threat than to non-threat words, whereas participants with higher levels of catastrophizing showed a similar cue validity effect for both threat and nonthreat words, with this effect being similar to the low catastrophizers' cue validity effect for threat words. Cue validity effects did not significantly depend on whether words were ambiguous or not. We found no catastrophizing-related differences in the impact of word ambiguity on cue validity effects.

Our hypothesis was based on the assumption of enhanced attention to threat relative to non-threat materials, especially in people with pain-related concerns or negative expectations about pain (control) (Pincus and Morley, 2001). Our 500-ms results are not compatible with this idea, but can be meaningfully interpreted with reference to two further notions in the anxiety literature. First, trait anxiety-related differences in attentional bias may become more apparent with general state anxiety and under stress (MacLeod and Mathews, 1988; Mogg et al., 1994; Fox et al., 2001; Broomfield and Turpin, 2005). Following this reasoning, an explanation for the absence of the predicted group difference in cue validity effects for threat words may involve low levels of distress and the absence of (anticipated) pain during testing. Second, anxious individuals may be characterized by excessive environmental scanning and a tendency to attend to any stimuli being presented (Weymar et al., 2014; Eysenck, 1997), possibly due to general difficulty in controlling attention (cf. Compton, 2000; Derryberry and Rothbart, 1988; Eysenck et al., 2007). It is logical to assume that also pain-related catastrophizing and fear/anxiety are associated with such general hypervigilance (Vlaeyen and Linton, 2000) or poor attentional control. The current results may be due to enhanced attention specifically to threat words by low catastrophizers, and enhanced attention to all stimuli, irrespective of threat content, by people with higher levels of catastrophizing. These explanations remain however speculative.

The observed attentional bias pattern for unambiguous words was not as predicted, which in turn makes it difficult to account for ambiguity-related findings. One might speculate that participants with higher levels of catastrophizing demonstrated enhanced attention to all stimuli, irrespective of perceived threat or ambiguity. Our observation of enhanced cue validity effects for unambiguous and ambiguous threat words as compared with unambiguous non-threat words in low catastrophizers fits with recent findings suggesting that also healthy low-anxious people may be inclined to show negative interpretation bias when confronted with somatic/health-related ambiguity (Vancleef et al., 2009). However, further research is undoubtedly needed to determine biased attention for pain/threat-related ambiguity in the context of consistent attention bias for unambiguous pain-related or threat stimuli. Such research is largely lacking, although there is one report suggesting sustained attention towards ambiguous as well as unambiguous angry facial stimuli in anxious individuals (Fox et al., 2002). The present study is the first specifically designed to evaluate attentional bias to ambiguous pain/threat-related information. Follow-up studies might also take into account intolerance of ambiguity, given the prediction that (pain-related) fear/anxiety is associated with intolerance of ambiguity (Grenier et al., 2005), characterized by biased attention to ambiguous information (Fergus et al., 2013).

Our main reason for including the 750-ms condition was to take into account the time course of ambiguous information processing. Evidence suggests that although both threat and non-threat meanings of ambiguous words are initially activated, it takes about 750 ms for one meaning to become dominant in highanxious individuals (Richards and French, 1992; Richards, 2004). We therefore expected attentional bias for ambiguous threat words to become apparent with 750-ms word presentations, and so with somewhat longer word presentation durations than attentional bias for unambiguous threat words. However, the present results provide no evidence for a different time course of attentional bias to unambiguous and ambiguous words. There were no attentional bias effects in the 750-ms condition.

There are not many attentional bias studies with long exposure durations $(>500 \mathrm{~ms})$ in the pain field (Crombez et al., 2013), and to our knowledge none with the single-cue modified spatial cueing task. In cueing tasks, the longer the stimulus presentation 
(and cue target interval), the more time there is to process stimulus content and the later attention is measured in time. So, under conditions allowing for more strategic processing and more shifting of attention, our analyses revealed no differential effects of word content or pain catastrophizing on attention. This result is largely in line with behavioural findings of studies with a double-cue modified spatial cueing task (or dot probe task) revealing no attentional bias for pain words and no association between such attentional bias and pain catastrophizing or pain-related fear/anxiety in healthy individuals or words presented longer than $500 \mathrm{~ms}$ (but also no significant bias effects with 500-ms stimulus duration: Roelofs et al., 2003 Exp. 2; Lees et al., 2005; or no shorter stimulus duration included: Yang et al., 2012).

We applied a single-cue modified spatial cueing task, one of today's most popular attentional bias paradigms. Although widely used, only few studies in the pain field used this task (Crombez et al., 2013), and to our knowledge none to assess bias to pain-related or somatic/health threat words in healthy individuals. The few studies that have used this task to examine attentional bias to pain-related information, considering individual differences in pain catastrophizing, revealed larger cue validity effects for conditioned pain signals as compared with safety signals, either only in high catastrophizers (Van Damme et al., 2004) or unassociated with level of catastrophizing (Van Ryckeghem et al., 2012). Divergent findings might be due to the degree of compatibility between the general construct measured with PCS and pain-related stimulus (context) during testing (Van Ryckeghem et al., 2012) and different experimental parameters. These previous studies differed from the current one in actual pain anticipation/experience, cue presentation duration, inclusion of a central fixation task (cf. Schrooten et al., 2012b) and type of required response (cf. Mulckhuyse and Crombez, 2014; Schrooten et al., 2012a). Previous studies with other paradigms than the single-cue modified spatial cueing task to examine attentional bias to pain-related or physical threat words, considering individual differences in pain catastrophizing, fear or anxiety sensitivity, produced seemingly inconsistent and inconclusive findings (Stewart et al., 1998; Keogh et al., 2001a, 2003; Keogh and Cochrane, 2002; Roelofs et al., 2002, 2003, 2005; Asmundson et al., 2005; Lees et al., 2005; Huber et al., 2010; Baum et al., 2011; Dear et al., 2011; Dittmar et al., 2011; Van Ryckeghem et al., 2012). These studies also largely differed in stimulus- and pain staterelated factors, and precise methods of assessment. Caution is therefore needed in directly comparing results across studies. More research is needed to systematically evaluate whether manipulation of certain experimental parameters indeed results in predictable and important differences in attention allocation.

Some study limitations should be noted. A larger and more gender-balanced sample, including more participants scoring in the highest ranges of catastrophizing (and related pain anxiety/fear constructs), would be helpful to further evaluate our hypotheses. The limited number of Dutch homographs and Dutch words that are unambiguously related to health/ somatic threat restricted options to match the lists of different word types in terms of word length, word frequency or homogeneity. It would be valuable for future studies to also use other types of ambiguous information, including ambiguous predictors of pain, to have participants themselves appraise stimulus materials, to include measures of how strongly each stimulus is associated with pain or threat (Crombez et al., 2013) and to include indices of the degree of stimulus ambiguity and assessment of ambiguous stimulus interpretation. Finally, it cannot be excluded that the presence of unambiguous threat words led to biased activation of the threat meaning of ambiguous words, and so actually disambiguated ambiguous threat/non-threat words. If so, this might explain the lack of an effect of ambiguity on attentional bias. Also the unpredicted results for unambiguous stimuli might be due to intermixed presentation with ambiguous stimuli. Future within-subject studies would benefit from presenting ambiguous and unambiguous stimuli in separate blocks.

In conclusion, in the current modified cueing task with 500-ms word presentation, low catastrophizers showed attentional bias to threat, whereas participants reporting higher catastrophizing showed overall enhanced attention. There was no evidence for the impact of word ambiguity on (biased) attention or for bias with 750-ms word duration. The present findings underline the importance of taking into account processing time and pain catastrophizing in evaluating pain/threat-related attentional bias, and call for further research on attentional bias for ambiguous pain/threat-related stimuli in the context of consistent attentional bias for unambiguous stimuli.

\section{Acknowledgements}

The authors thank Jacco Ronner for technical support; Judith Beurskens, Kelian Reijerse, Lotte Pustjens, Marlotte van Muijden, Rick de Greef, Sophie Thijs and Jörgen Satijn for their help in stimulus selection, participant recruitment and/or data collection; Professor Stephen Morley and one 
anonymous reviewer for comments on an earlier version of the manuscript.

\section{Author contributions}

M.G.S.S. and L.V. conceived and designed the experiment. M.G.S.S. and L.V. performed the experiment. M.G.S.S. analysed the data. M.G.S.S., L.V. and J.W.S.V. wrote the manuscript. All authors discussed the results and commented on the manuscript.

\section{References}

Amir, N., Elias, J., Klumpp, H., Przeworski, A. (2003). Attentional bias to threat in social phobia: Facilitated processing of threat or difficulty disengaging attention from threat? Behav Res Ther 41, 1325-1335.

Asmundson, G.J., Bovell, C.V., Carleton, R.N., McWilliams, L.A. (2008). The Fear of Pain Questionnaire-Short Form (FPQ-SF): Factorial validity and psychometric properties. Pain 134, 51-58.

Asmundson, G.J., Wright, K.D., Hadjistavropoulos, H.D. (2005). Hypervigilance and attentional fixedness in chronic musculoskeletal pain: Consistency of findings across modified stroop and dot-probe tasks. $J$ Pain 6, 497-506.

Baum, C., Huber, C., Schneider, R., Lautenbacher, S. (2011). Prediction of experimental pain sensitivity by attention to pain-related stimuli in healthy individuals. Percept Mot Skills 112, 926-946.

Boston, A., Sharpe, L. (2005). The role of threat-expectancy in acute pain: Effects on attentional bias, coping strategy effectiveness and response to pain. Pain 119, 168-175.

Broomfield, N.M., Turpin, G. (2005). Covert and overt attention in trait anxiety: A cognitive psychophysiological analysis. Biol Psychol 68, 179200.

Burns, J.W., Quartana, P.J., Elfant, E., Matsuura, J., Gilliam, W., Nappi, C., Wolff, B., Gray, E. (2010). Shifts in attention biases in response to acute pain induction: Examination of a model of 'conversion' among repressors. Emotion 10, 755-766.

Carleton, R.N., Asmundson, G.J.G., Taylor, S. (2005). Fear of physical harm: Factor structure and psychometric properties of the injury/illness sensitivity index. J Psychopathol Behav Assess 27, 235-241.

Compton, R.J. (2000). Ability to disengage attention predicts negative affect. Cogn Emotion 14, 401-415.

Crombez, G., Van Ryckeghem, D.M., Eccleston, C., Van Damme, S. (2013). Attentional bias to pain-related information: A meta-analysis. Pain 154, 497-510.

Dear, B.F., Sharpe, L., Nicholas, M.K., Refshauge, K. (2011). Pain-related attentional biases: The importance of the personal relevance and ecological validity of stimuli. J Pain 12, 625-632.

Derryberry, D., Rothbart, M.K. (1988). Arousal, affect, and attention as components of temperament. J Pers Soc Psychol 55, 958-966.

Dittmar, O., Krehl, R., Lautenbacher, S. (2011). Interrelation of selfreport, behavioural and electrophysiological measures assessing painrelated information processing. Pain Res Manag 16, 33-40.

Eccleston, C., Crombez, G. (1999). Pain demands attention: A cognitiveaffective model of the interruptive function of pain. Psychol Bull 125 , 356-366.

Ellenbogen, M.A., Schwartzman, A.E. (2009). Selective attention and avoidance on a pictorial cueing task during stress in clinically anxious and depressed participants. Behav Res Ther 47, 128-138.

Eysenck, M. (1997). Anxiety and Cognition: A Unified Theory (Hove: Psychology Press)

Eysenck, M.W., Derakshan, N., Santos, R., Calvo, M.G. (2007). Anxiety and cognitive performance: Attentional control theory. Emotion 7, 336353.

Fergus, T.A., Bardeen, J.R., Wu, K.D. (2013). Intolerance of uncertainty and uncertainty-related attentional biases: Evidence of facilitated engagement or disengagement difficulty? Cogn Ther Res 37, 735-741.
Fox, E., Russo, R., Bowles, R., Dutton, K. (2001). Do threatening stimuli draw or hold visual attention in subclinical anxiety? J Exp Psychol Gen $130,681-700$.

Fox, E., Russo, R., Dutton, K. (2002). Attentional bias for threat: Evidence for delayed disengagement from emotional faces. Cogn Emotion 16, 355-379.

Grenier, S., Barrette, A.M., Ladouceur, R. (2005). Intolerance of uncertainty and intolerance of ambiguity: Similarities and differences. Pers Individ Dif 39, 593-600.

Hermans, D., De Houwer, J. (1994). Affective and subjective familiarity ratings of 740 Dutch words. Psychol Belg 34, 115-139.

Huber, C., Kunz, M., Artelt, C., Lautenbacher, S. (2010). Attentional and emotional mechanisms of pain processing and their related factors: A structural equations approach. Pain Res Manag 15, 229-237.

Keogh, E., Cochrane, M. (2002). Anxiety sensitivity, cognitive biases, and the experience of pain. J Pain 3, 320-329.

Keogh, E., Dillon, C., Georgiou, G., Hunt, C. (2001a). Selective attentional biases for physical threat in physical anxiety sensitivity. $J$ Anxiety Disord 15, 299-315.

Keogh, E., Ellery, D., Hunt, C., Hannent, I. (2001b). Selective attentional bias for pain-related stimuli amongst pain fearful individuals. Pain 91, 91-100.

Keogh, E., Hamid, R., Hamid, S., Ellery, D. (2004). Investigating the effect of anxiety sensitivity, gender and negative interpretative bias on the perception of chest pain. Pain 111, 209-217.

Keogh, E., Thompson, T., Hannent, I. (2003). Selective attentional bias, conscious awareness and the fear of pain. Pain 104, 85-91.

Klein, R.M. (2000). Inhibition of return. Trends Cogn Sci 4, 138-147.

Klein, R.M., Taylor, T.L. (1994). Categories of cognitive inhibition with reference to attention. In Inhibitory Processes in Attention, Memory, and Language, D. Dagenbach, T.H. Carr, eds. (San Diego: Academic Press) pp. 113-150.

Koster, E.H., Leyman, L., De Raedt, R.D., Crombez, G. (2006). Cueing of visual attention by emotional facial expressions: The influence of individual differences in anxiety and depression. Pers Individ Dif 41, 329339.

Lees, A., Mogg, K., Bradley, B.P. (2005). Health anxiety, anxiety sensitivity, and attentional biases for pictorial and linguistic health-threat cues. Cogn Emotion 19, 453-462.

MacLeod, C., Mathews, A. (1988). Anxiety and the allocation of attention to threat. Q J Exp Psychol 40, 653-670.

Martin, M., Chapman, S.C. (2010). Cognitive processing in putative functional gastrointestinal disorder: Rumination yields orientation to social threat not pain. Eur J Pain 14, 207-213.

Mathews, A., Mackintosh, B. (1998). A cognitive model of selective processing in anxiety. Cogn Ther Res 22, 539-560.

Mogg, K., Bradley, B.P., Hallowell, N. (1994). Attentional bias to threat: Roles of trait anxiety, stressful events, and awareness. Q J Exp Psychol 47, 841-864.

Mulckhuyse, M., Crombez, G. (2014). Disentangling attention from action in the emotional spatial cueing task. Cogn Emot 28, 1223 1241

Osman, A., Barrios, F.X., Kopper, B.A., Hauptmann, W., Jones, J., O’Neill, E. (1997). Factor structure, reliability, and validity of the Pain Catastrophizing Scale. J Behav Med 20, 589-605.

Peterson, R.A., Reiss, S. (1992). Anxiety sensitivity index manual. International Diagnostic Systems, Worthington, $\mathrm{OH}$.

Pincus, T., Morley, S. (2001). Cognitive-processing bias in chronic pain: A review and integration. Psychol Bull 127, 599-617.

Posner, M.I., Inhoff, A.W., Friedrich, F.J., Cohen, A. (1987). Isolating attentional systems: A cognitive-anatomical analysis. Psychobiol 15, 107-121.

Posner, M.I., Snyder, C.R., Davidson, B.J. (1980). Attention and the detection of signals. J Exp Psychol Gen 109, 160-174.

Richards, A. (2004). Anxiety and the resolution of ambiguity. In Cognition, Emotion, and Psychopathology: Theoretical, Empirical, and Clinical Directions, J. Yiend, ed. (Cambridge: Cambridge University Press) pp. 130-148.

Richards, A., French, C.C. (1992). An anxiety-related bias in semantic activation when processing threat/neutral homographs. Q J Exp Psychol A 45, 503-525. 
Roelofs, J., Peters, M.L., Fassaert, T., Vlaeyen, J.W. (2005). The role of fear of movement and injury in selective attentional processing in patients with chronic low back pain: A dot-probe evaluation. J Pain 6, 294-300.

Roelofs, J., Peters, M.L., van der Zijden, M., Thielen, F.G., Vlaeyen, J.W. (2003). Selective attention and avoidance of pain-related stimuli: A dot-probe evaluation in a pain-free population. J Pain 4, 322-328.

Roelofs, J., Peters, M.L., Vlaeyen, J.W. (2002). Selective attention for pain-related information in healthy individuals: The role of pain and fear. Eur J Pain 6, 331-339.

Schoth, D.E., Nunes, V.D., Liossi, C. (2012). Attentional bias towards pain-related information in chronic pain: A meta-analysis of visualprobe investigations. Clin Psychol Rev 32, 13-25.

Schrooten, M.G., Smulders, F.T. (2009). Biased processing of emotional information in sub-clinical anxiety: Evidence from Simon effects. Pers Indiv Diff 47, 691-696.

Schrooten, M.G., Smulders, F.T. (2010). Temporal dynamics of selective attention in non-clinical anxiety. Pers Indiv Diff 48, 213-217.

Schrooten, M.G., Smulders, F.T., Mogg, K., Bradley, B.P. (2012a). Anxiety-related biases in visual orienting and spatial motor response selection independently assessed by a probe-classification task. $J$ Exp Psychopathol 3, 393-408.

Schrooten, M.G., Van Damme, S., Crombez, G., Peters, M.L., Vogt, J., Vlaeyen, J.W. (2012b). Nonpain goal pursuit inhibits attentional bias to pain. Pain 153, 1180-1186.

Stewart, S.H., Conrod, P.J., Gignac, M.L., Pihl, R.O. (1998). Selective processing biases in anxiety-sensitive men and women. Cogn Emot 12, 105-134.

Sullivan, M.J., Bishop, S.R., Pivik, J. (1995). The pain catastrophizing scale: Development and validation. Psychol Assess 7, 524-532.

Van Damme, S., Crombez, G., Bijttebier, P., Goubert, L., Van Houdenhove, B. (2002). A confirmatory factor analysis of the pain catastrophizing scale: Invariant factor structure across clinical and non-clinical populations. Pain 96, 319-324.

Van Damme, S., Crombez, G., Eccleston, C. (2004). Disengagement from pain: The role of catastrophic thinking about pain. Pain 107, 70-76.

Van Damme, S., Crombez, G., Vlaeyen, J.W.S., Goubert, L., Van den Broeck, A., Van Houdenhove, B. (2000). De Pain Catastrophizing Scale: Psychometrische karakteristieken en normering. [The Pain Catastrophizing Scale: Psychometric characteristics and norm scores]. Gedragstherapie 33, 211-222.

Van Damme, S., Legrain, V., Vogt, J., Crombez, G. (2010). Keeping pain in mind: A motivational account of attention to pain. Neurosci Biobehav Rev 34, 204-213.
Van Ryckeghem, D.M., Crombez, G., Van Hulle, L., Van Damme, S. (2012). Attentional bias towards pain-related information diminishes the efficacy of distraction. Pain 153, 2345-2351.

Vancleef, L.M., Peters, M.L., De Jong, P.J. (2009). Interpreting ambiguous health and bodily threat: Are individual differences in pain-related vulnerability constructs associated with an on-line negative interpretation bias? J Behav Ther Exp Psychiatry 40, 59-69.

Vancleef, L.M.G., Peters, M.L., Gilissen, S.M.P., De Jong, P.J. (2007). Understanding the role of injury/illness sensitivity and anxiety sensitivity in (automatic) pain processing: An examination using the extrinsic affective Simon task. J Pain 8, 563-572.

Vlaeyen, J.W., Linton, S.J. (2000). Fear-avoidance and its consequences in chronic musculoskeletal pain: A state of the art. Pain 85, 317-332.

Vlaeyen, J.W., Linton, S.J. (2012). Fear-avoidance model of chronic mus culoskeletal pain: 12 years on. Pain 153, 1144-1147.

Walton, D.M., Wideman, T.H., Sullivan, M.J. (2013). A Rasch analysis of the pain catastrophizing scale supports its use as an interval-level measure. Clin J Pain 29, 499-506.

Waters, A.M., Nitz, A.B., Craske, M.G., Johnson, C. (2007). The effects of anxiety upon attention allocation to affective stimuli. Behav Res Ther 45 , 763-774.

Weymar, M., Keil, A., Hamm, A.O. (2014). Timing the fearful brain Unspecific hypervigilance and spatial attention in early visual perception. Soc Cogn Affect Neurosci 9, 723-729.

Yang, Z., Jackson, T., Gao, X., Chen, H. (2012). Identifying selective visual attention biases related to fear of pain by tracking eye movements within a dot-probe paradigm. Pain 153, 1742-1748.

Yantis, S. (1996). Control of visual attention. In Attention, H. Pashler, ed. (San Diego: Psychology Press) pp. 223-256.

Yiend, J., Mathews, A. (2001). Anxiety and attention to threatening pictures. Q J Exp Psychol A 54, 665-681.

\section{Supporting Information}

Additional Supporting Information may be found in the online version of this article at the publisher's web-site:

Appendix S1. Analyses of variance: word type (3). 